\title{
VIBRATIONAL MEASUREMENTS IN 3-ID-B
}

\section{J. Sutter ${ }^{1}$, E. Alp ${ }^{1}$, J. Barraza ${ }^{2}$, D. Shu ${ }^{2}$}

\section{INTRODUCTION}

We have undertaken a series of vibrational measurements in hutch 3-ID-B. Our motivation was to compare two different methods of mounting an interferometer for effectiveness in vibrational isolation and stability. In addition, we were able to compare the stability of our optical table with and without its eight large bolts inserted.

\section{PROCEDURE}

We used two accelerometers to measure the amplitude of the vibrational acceleration as a function of frequency in steps of $0.0625 \mathrm{~Hz}$ from 1 to $25 \mathrm{~Hz}$. The accelerations could then be transformed into displacement amplitudes by the simple harmonic equation of motion $\ddot{x}=$ $-\omega^{2} x$, where $x$ is the displacement and $\omega$ is the frequency times $2 \pi$. The accelerometers had been calibrated before our experiment and were found to output a voltage of $(7.44 G) \mathrm{V} / g$, where $G$ is the sensor gain (100 in our experiment) and $g=9.8 \mathrm{~m} / \mathrm{s}^{2}$ is the acceleration due to gravity.

\section{RESULTS}

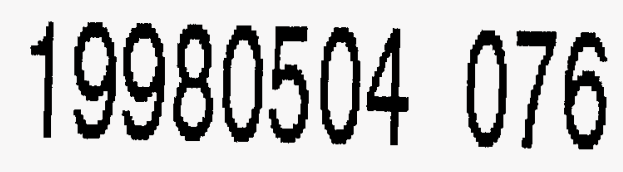

\section{Table Vibrations}

The measurements reported in this section were taken on December 6, 1997. On that day, the APS was not in operation, as the linac. PAR, and booster were all open for access. Therefore, these machines would not have created any noise that could have affected our measurements. However, the table itself was equipped with six motors to permit automated control of the

\footnotetext{
${ }^{1}$ SRI-CAT, Sector 3

2 APS-XFD Beamline Engineering Group
}

\section{EISTRIBUTION OF THIS DOCUMINT IS UNLIMITED}
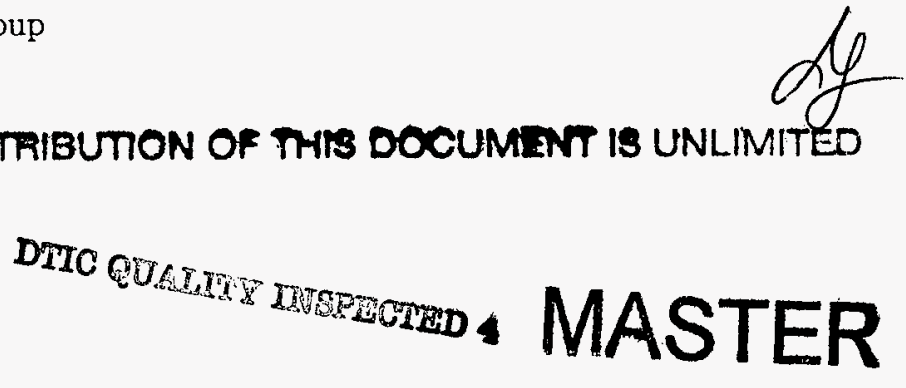


\section{DISCLAIMER}

This report was prepared as an account of work sponsored by an agency of the United States Government. Neither the United States Government nor any agency thereof, nor any of their employees, makes any warranty, express or implied, or assumes any legal liabjlity or responsibility for the accuracy, completeness, or usefulness of any information, apparatus, product, or process disclosed, or represents that its use would not infringe privately owned rights. Reference herein to any specific commercial product, process, or service by trade name, trademark, manufacturer, or otherwise does not necessarily constitute or imply its endorsement, recommendation, or favoring by the United States Government or any agency thereof. The views and opinions of authors expressed herein do not necessarily state or reflect those of the United States Government or any agency thereof. 
table's position and angle. Because these motors could also have produced vibrations on the table top and because they would normally be turned on in an actual experiment, we left them on during our vibrational measurements. We checked the vibrations of our optical table top in three orthogonal directions: vertical, horizontal upstream (parallel to the beam), and horizontal outboard (perpendicular to the beam). We will abbreviate these names as $\mathrm{V}$, $\mathrm{HU}$, and $\mathrm{HO}$, respectively.

The outer frame of our optical table had tapped holes for eight large bolts whose purpose was to stabilize the inner frame and stages to which the table top was mounted. We wished to understand how these bolts would affect the table top's tendency to vibrate if they were inserted. For vibrations in the $\mathrm{V}$ and $\mathrm{HO}$ directions, we collected data before and after the bolts were inserted. For vibrations in the HU direction, we have only data taken after the bolts were inserted.

Figures 1 and 2 plot the vibrational spectra in the $V$ direction on the optical table and on the hutch floor, respectively. Figures 3 and 4 are the corresponding plots for the HO direction, and figures 5 and 6 are the ones for the HU direction. Figures 1,3 , and 5 show that the most important feature of the vibrational spectra that is affected by the insertion of the bolts is the broad peak around $14.3 \mathrm{~Hz}$. This peak may be seen in both the $\mathrm{V}$ and HO table top spectra taken without the bolts, though it is more pronounced in the HO direction. However, in no vibrational spectrum taken with the bolts inserted is any similarly broad peak visible. Inserting the bolts also raised the low-frequency $(1-5 \mathrm{~Hz}) \mathrm{HO}$ vibrational amplitudes by approximately a factor of three and reduced the low-frequency $\mathrm{V}$ vibrational amplitudes by about the same factor. Finally, inserting the bolts raised the high-frequency $(20-25 \mathrm{~Hz}) \mathrm{HO}$ vibrational amplitudes by up to an order of magnitude, although here these amplitudes are very small $\left(<10^{-3} \mu \mathrm{m}\right)$.

Several other features of the table top vibrational spectra are not similarly affected by the presence of the bolts. The first is the tendency of the vibrational amplitudes to rise as the frequency is decreased from about $6-7 \mathrm{~Hz}$. This trend can be seen in the vibrational spectra taken from all three directions. The second is the appearance of several sharp peaks in the $\mathrm{HO}$ and $\mathrm{V}$ spectra. The most notable of these appear at $18.562 \mathrm{~Hz}, 19.812 \mathrm{~Hz}$, and 
$22.562 \mathrm{~Hz}$ in the $\mathrm{HO}$ direction, and at $18.562 \mathrm{~Hz}$ and $19.812 \mathrm{~Hz}$ in the $\mathrm{V}$ direction. (Peaks at $18.562 \mathrm{~Hz}$ and $19.812 \mathrm{~Hz}$ can also be seen in the $\mathrm{HU}$ spectrum.) Because the bolts do not affect them, they must originate from some source outside the table itself. Although we have not undertaken an exhaustive search for the sources of the different vibrations, we have checked the vibrations of the concrete hutch floor close to the table. Figures 2, 4, and 6 show the rise in the floor's vibrational amplitude at lower frequencies; they also show peaks of the same frequency and comparable amplitude as the table top peaks mentioned above. We conclude that these features in the table top vibrations, which were not altered by the bolts, were transmitted to the table top from the floor.

\section{Interferometer Platform Vibrations}

Our chief aim in performing this study was to compare two different methods of mounting a triple Laue interferometer for use in 3-ID-B. Like most interferometers, the triple Laue is very sensitive to vibration; therefore, its mount must keep the vibration level as low as possible. At the same time, however, the mount must permit adjustment of the angle of the interferometer with respect to the incident beam.

Our setup is shown in Fig. 7. The optical table we have described above was mounted on the concrete floor of the hutch. On top of the table, we placed a Huber 5204.2 double-tilt stage. This stage weighed $26 \mathrm{~kg}$, not including the motors, and was itself placed on a pair of aluminum wedges inclined at $13^{\circ}$ from the horizontal. These wedges allowed the Bragg angle tilt of the stage to reach $27^{\circ}$, the Bragg angle of our triple Laue interferometer. Because the three motors installed on the Huber stage would normally be active during an experiment, they were left on during our measurements, as were the optical table motors.

The Huber stage was so constructed that its center of rotation was $152 \mathrm{~mm}$ above the stage platform. Therefore, some way of raising the interferometer to this height had to be devised, and we have found the two different systems that we will compare below. Both of these setups may be seen in Fig. 8. Our first solution was to make an aluminum platform $1 / 4$ " thick and support it with four corner posts also made of aluminum. These posts were screwed into the tapped corner holes of the Huber stage platform and held in place at the top with nuts. The aluminum platform had holes drilled in a pattern that allowed a $1 / 8$ "-thick 
aluminum bracket to be mounted. Against this bracket, an aluminum spacer was placed. This spacer was held in place at the sides by a pair of restrainers screwed into the platform. The interferometer itself was mounted freely on top of the spacer and against the bracket, where the bracket could keep the interferometer from falling off the platform.

Our second solution was based on the premise that, by making the interferometer support as stiff as possible, we could reduce the vibrational amplitudes felt by the interferometer. As a result, all the new mounting parts were made from low-carbon steel, whose modulus of elasticity is two to three times greater than that of aluminum. (Stainiess steel was not used because of the greater expense of obtaining and machining it.) Steel has the additional advantage of having a much lower thermal expansion coefficient than aluminum, so that mounts made from it can be more resistant to temperature gradients. The new design consisted of a base plate screwed to the Huber stage platform, a 6"-diameter steel cylinder screwed to the base plate, and a $1 / 2$ "-thick steel platform on top. The interferometer was mounted to this platform with the aid of a spacer held by a pair of side restrainers and a bracket, just as in the first setup. However, the spacer and the bracket were also made of steel, and the bracket was made $1 / 4$ " thick and given triangular side braces to prevent it from bending. The increased thickness added to the stiffness of the parts.

The vibrational spectra on the aluminum mount were taken on December 6, 1997, under the synchrotron operating conditions discussed above. They were also taken with no bolts inserted in the optical table. The vibrational spectra on the steel mount, however, were taken on January 9, 1998. On that date, the linac, PAR, and booster enclosures were all closed, and machine studies were taking place. In addition, the bolts were inserted in the optical table on that day. These factors mean that a direct comparison of the aluminum mount and the steel mount will not be possible. However, we still have sufficient data to indirectly check the two mounts: ability to suppress vibrations. Our strategy will be to compare each vibrational spectrum on the interferometer platform with the corresponding spectrum on the optical table top taken on the same day and under the same conditions. Here we make one final note: because the interferometer platform is tilted by $27^{\circ}$ from the horizontal about the axis perpendicular to the incident beam, the vertical (V) and horizontal upstream (HU) 
directions on the interferometer platform are tilted by the same amount relative to the $\mathrm{V}$ and $\mathrm{HU}$ directions on the optical table top (Figure 7).

First, we examine the V vibrations. Figure 9, which compares the V spectra of the table top and the aluminum interferometer platform, shows a significant increase in the vibrational amplitudes from the table to the platform, particularly at frequencies below $10 \mathrm{~Hz}$. On the other hand, Fig. 10, the plot of the V spectra for the table top and the steel interferometer platform, shows these two spectra to be of similar intensity over nearly the whole range from 1 to $25 \mathrm{~Hz}$. Only over the short ranges between 3 and $7 \mathrm{~Hz}$, and between 23 and $25 \mathrm{~Hz}$, is the steel platform $\mathrm{V}$ spectrum significantly more intense than that of the table, and then only by a small factor.

For the HO vibrational spectra, the results are similar. From the optical table top to the aluminum platform (Fig. 11), the vibrational amplitudes are increased over the entire recorded frequency range. From the optical table top to the steel platform, however (Fig. 12), the vibrational amplitudes are actually reduced below $7 \mathrm{~Hz}$, and only above $15 \mathrm{~Hz}$ do the amplitudes increase again.

For the HU vibrational spectra, there is some extra difficulty because on December 6, 1997, we did not collect an HU spectrum on the table top with the bolts not inserted. We did, however, collect such a spectrum on the steel top of the Huber stage to which the aluminum platform was mounted, and we did this on the same day that we took an HU spectrum on the aluminum platform itself. Consequently, for the results of December 6, 1997, this is the comparison we make. The plot of these two HU spectra (Fig. 13) shows an increase in vibrational amplitude over the whole recorded frequency range from the Huber stage top to the aluminum platform, similar to that found in the HO spectra. Comparing the optical table top HU spectrum taken on January 9, 1998 to the steel platform HU spectrum taken the same day, however, shows comparable vibrational amplitudes up to $1.5 \mathrm{~Hz}$, above which the steel platform vibrations become stronger by a small factor (Fig. 14).

From these results, we may conclude that the steel platform is more stable than the aluminum platform. The steel platform still shows greater vibration above $15 \mathrm{~Hz}$, but the plots show that, in this frequency range, the amplitudes are generally small $\left(<10^{-3} \mu \mathrm{m}\right)$. 


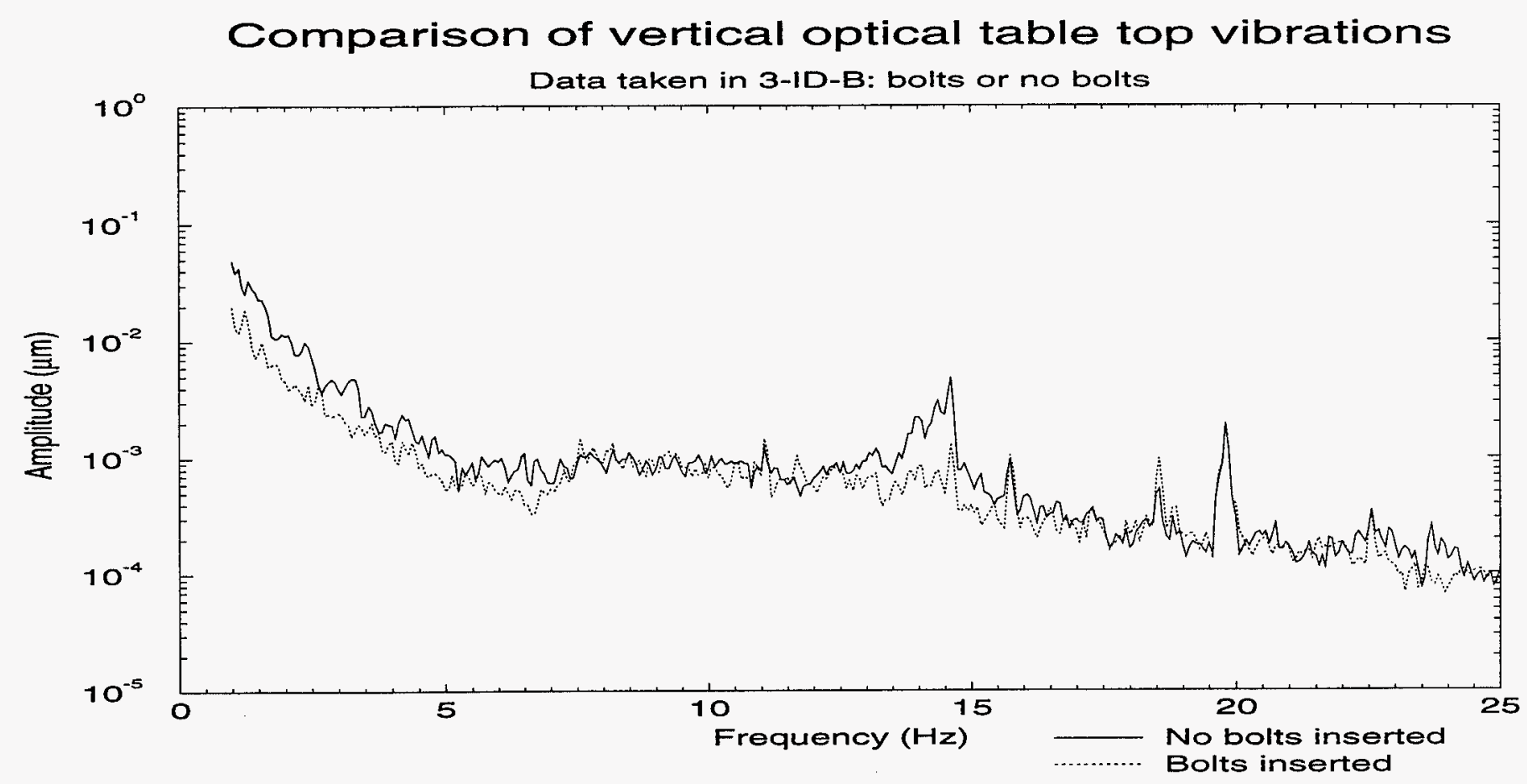

Figure 1: V vibrational spectra on table

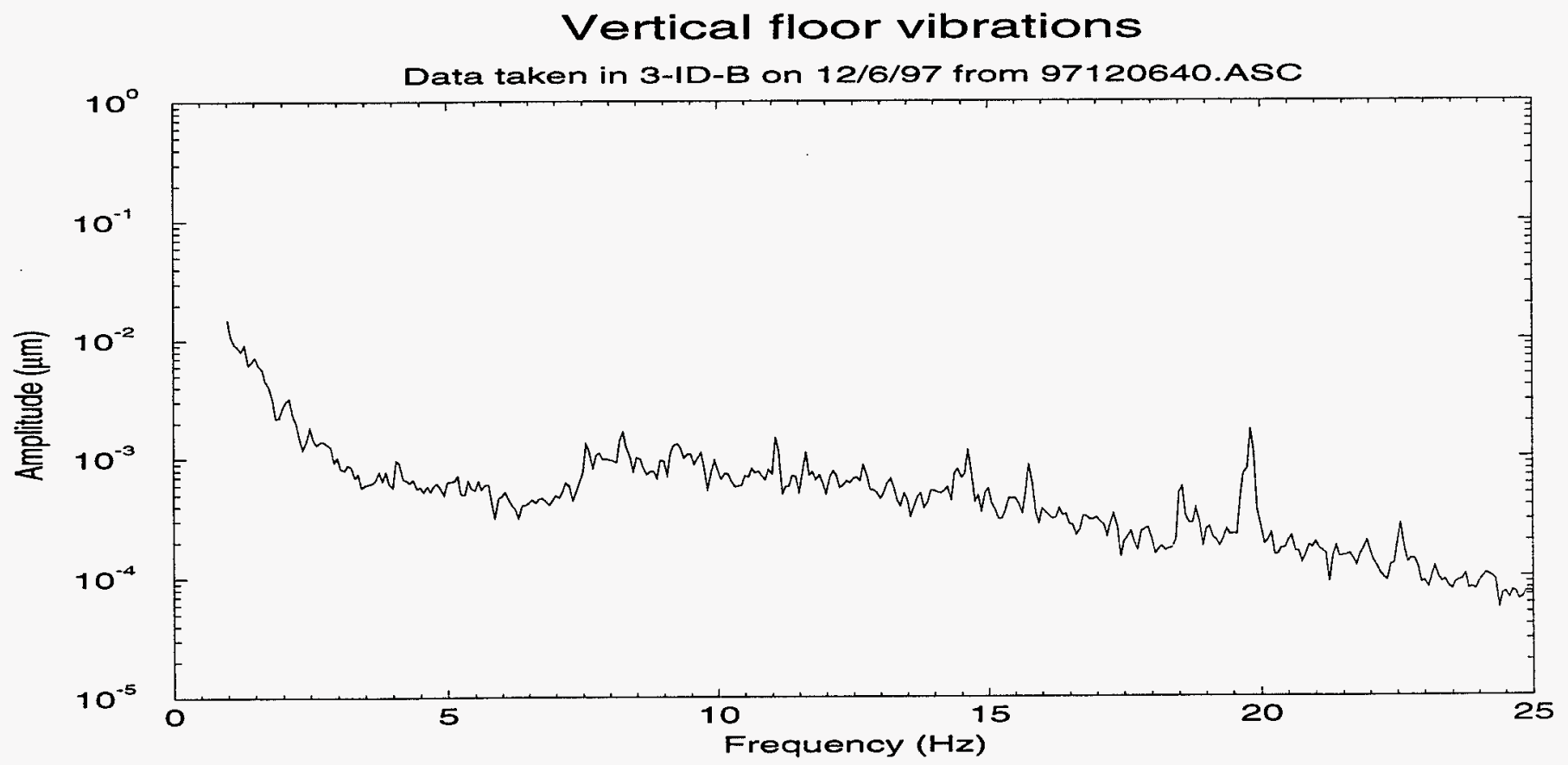

Figure 2: V vibrational spectrum on floor 
Comparison of horiz. outboard optical table top vibrations

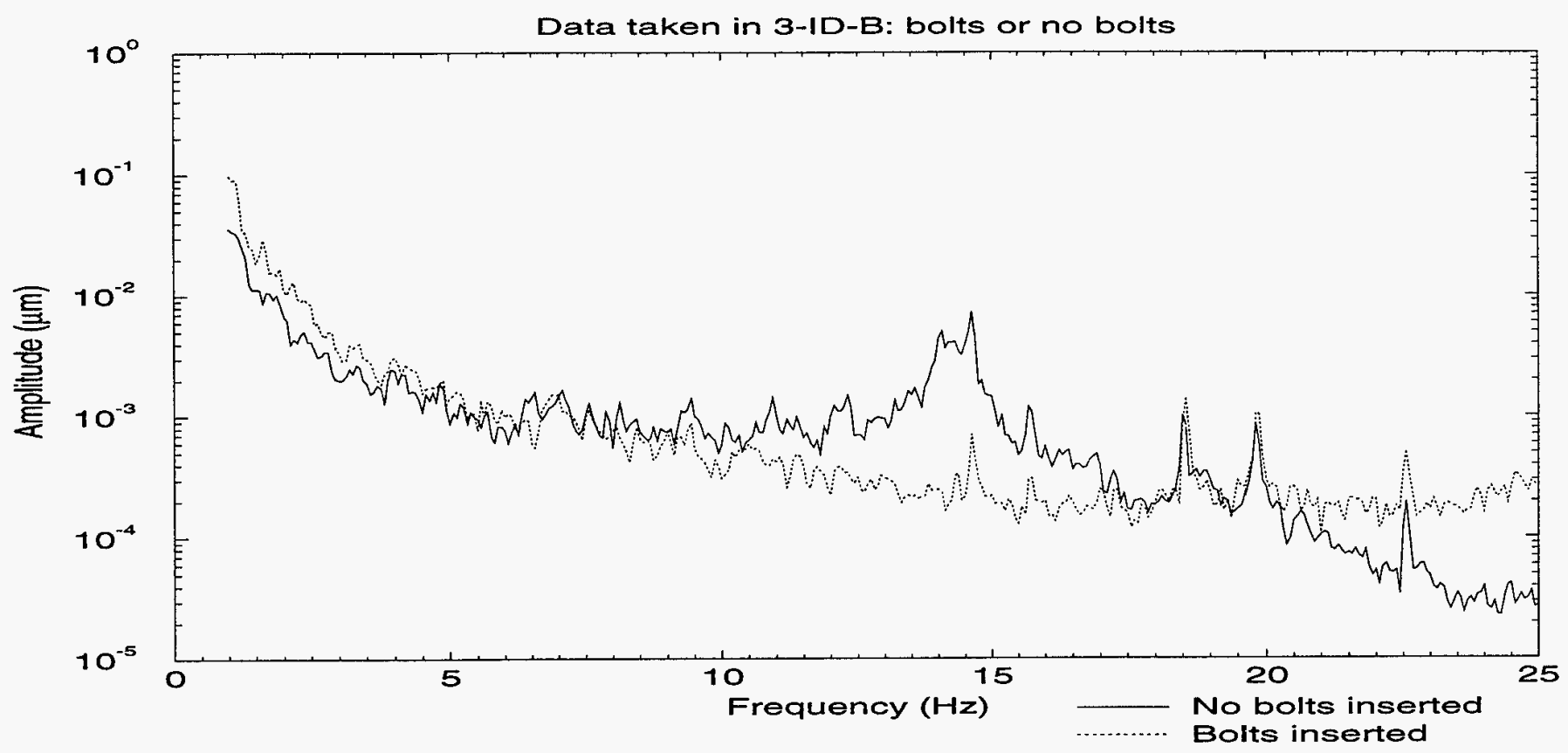

Figure 3: HO vibrational spectra on table

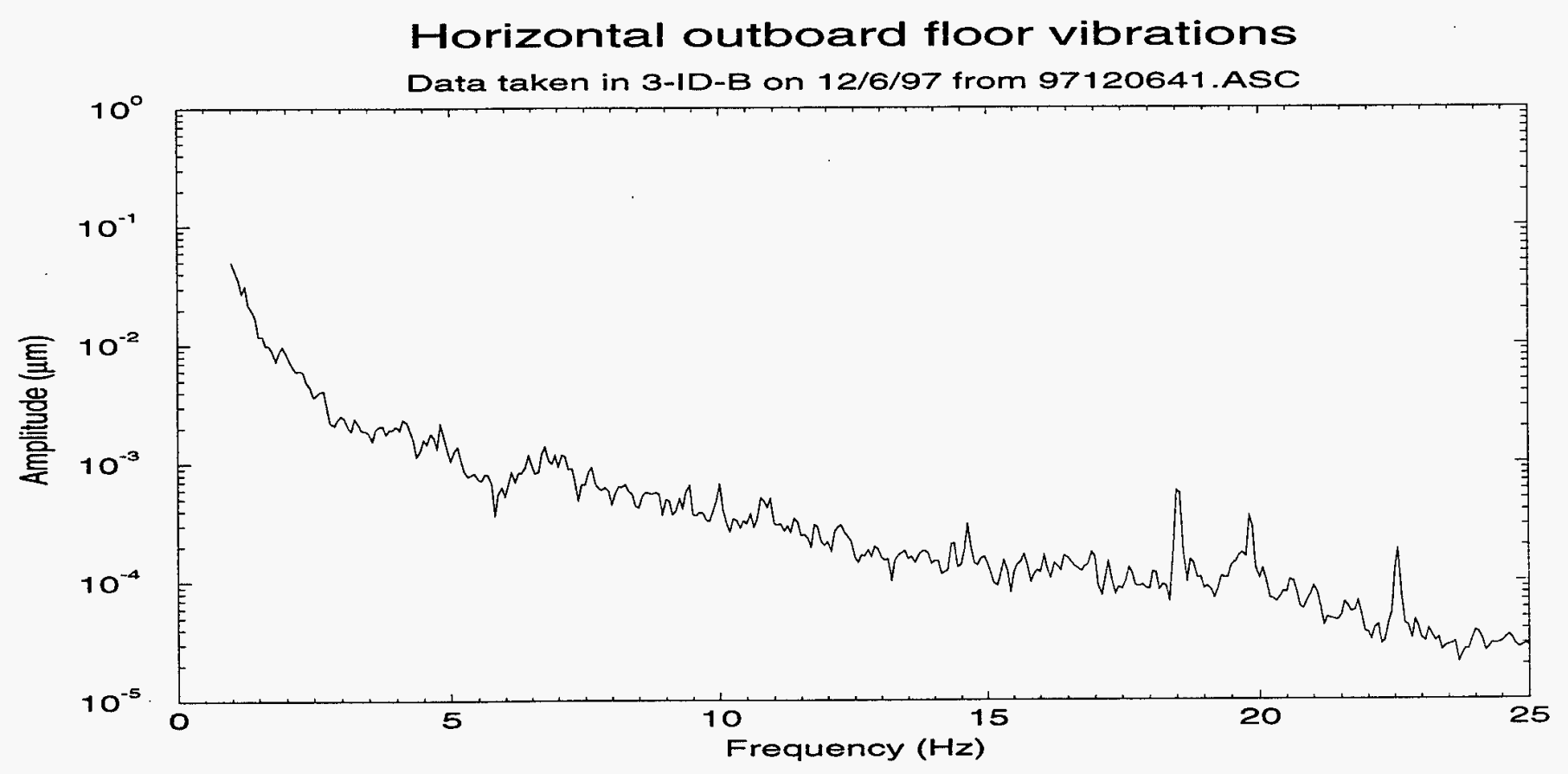

Figure 4: HO vibrational spectrum on floor 
Horiz. upstream optical table top vibrations

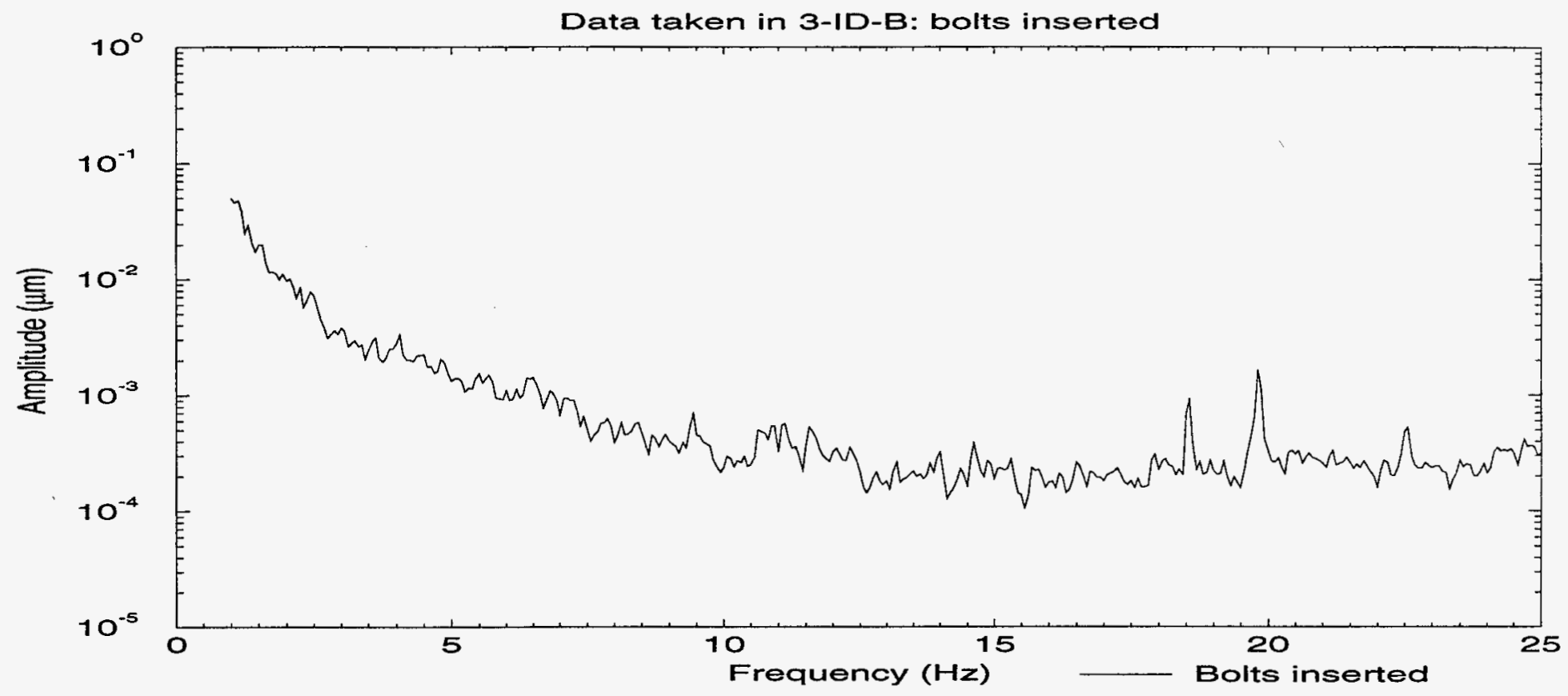

Figure 5: $\mathrm{HU}$ vibrational spectrum on table

\section{Horizontal upstream floor vibrations}

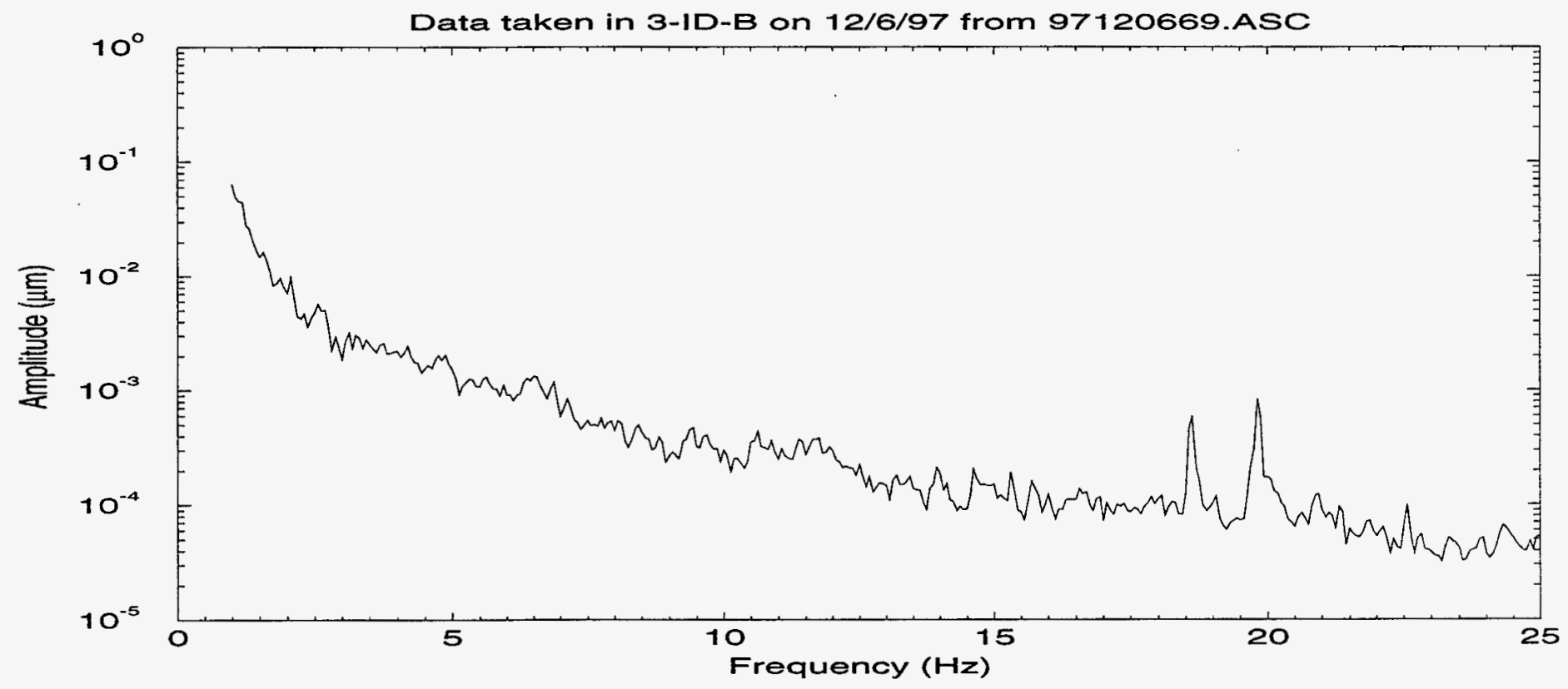

Figure 6: HU vibrational spectrum on floor 


\section{SETUP FOR VIBRATIONAL MEASUREMENTS IN HUTCH 3-ID-B}

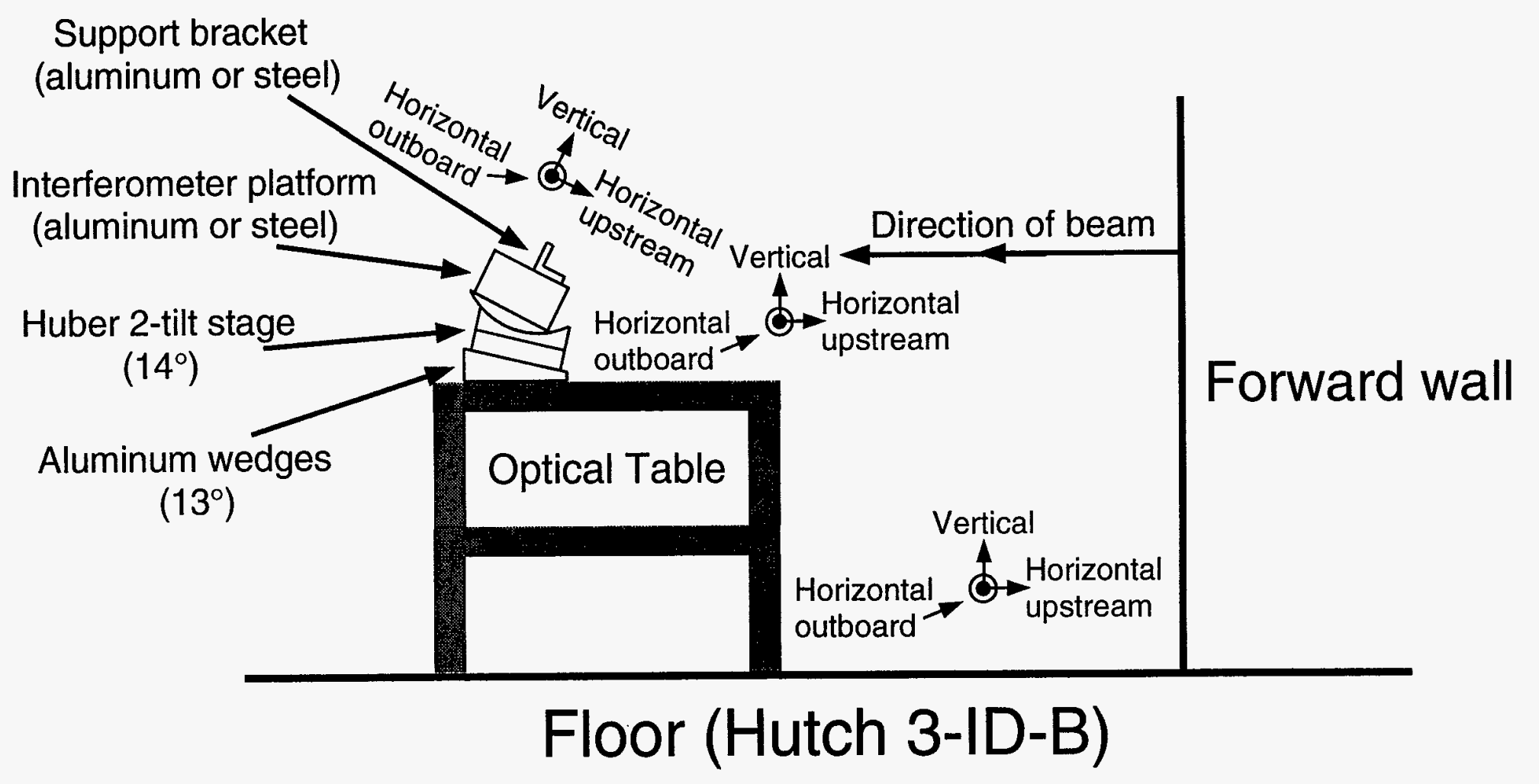




\section{ALUMINUM INTERFEROMETER MOUNT}

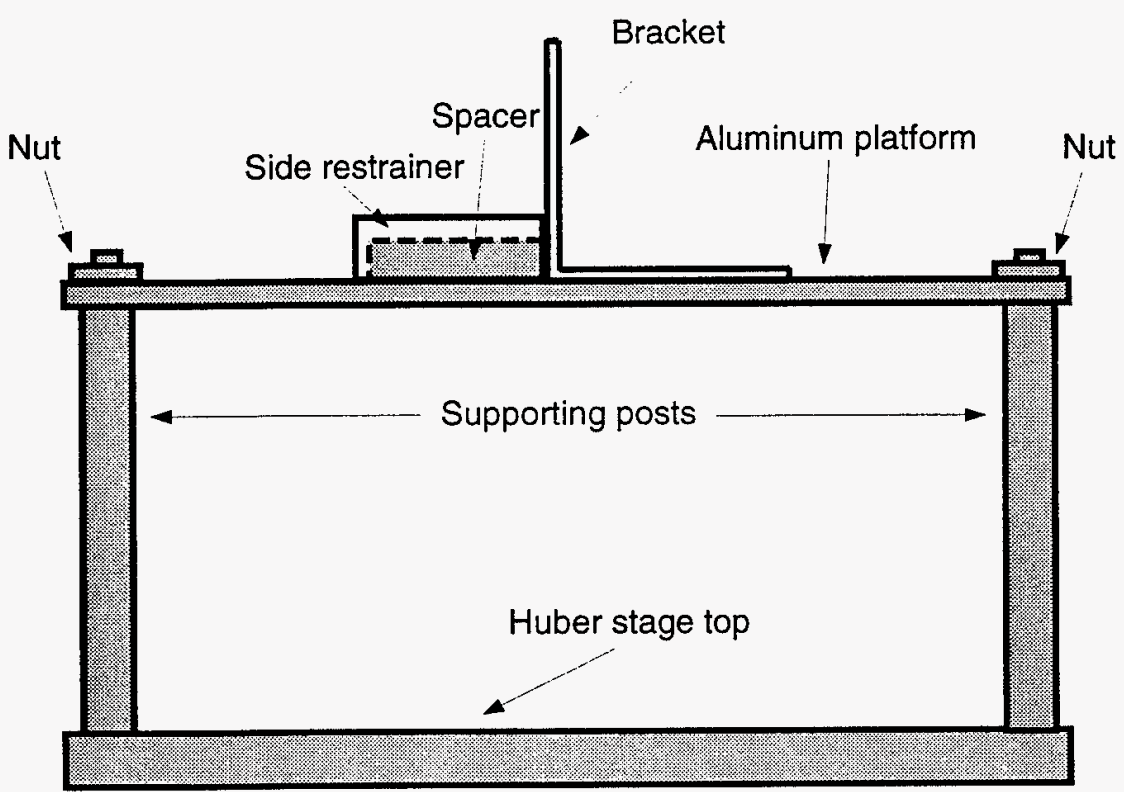

\section{STEEL INTERFEROMETER MOUNT}

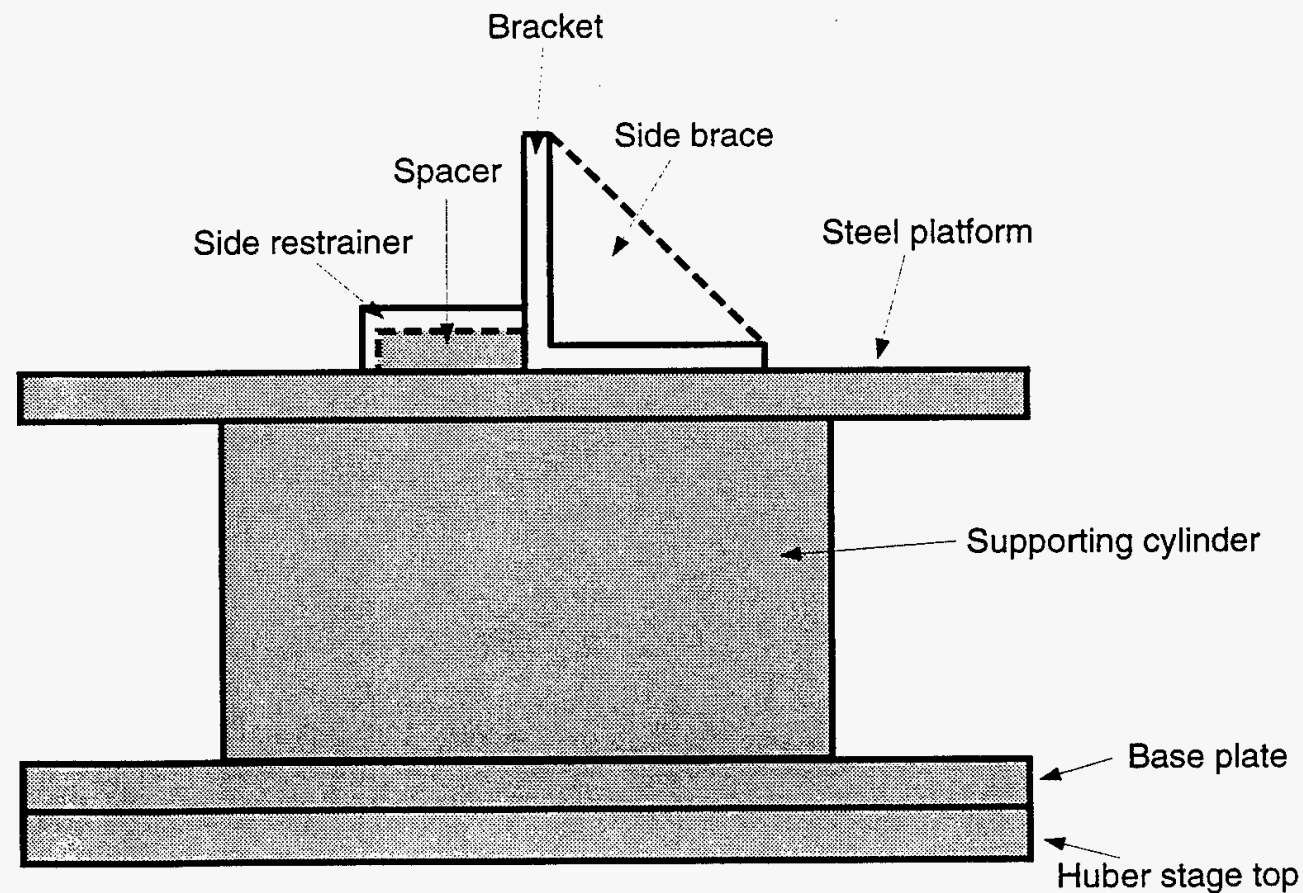

Figure 8: Interferometer mounts 


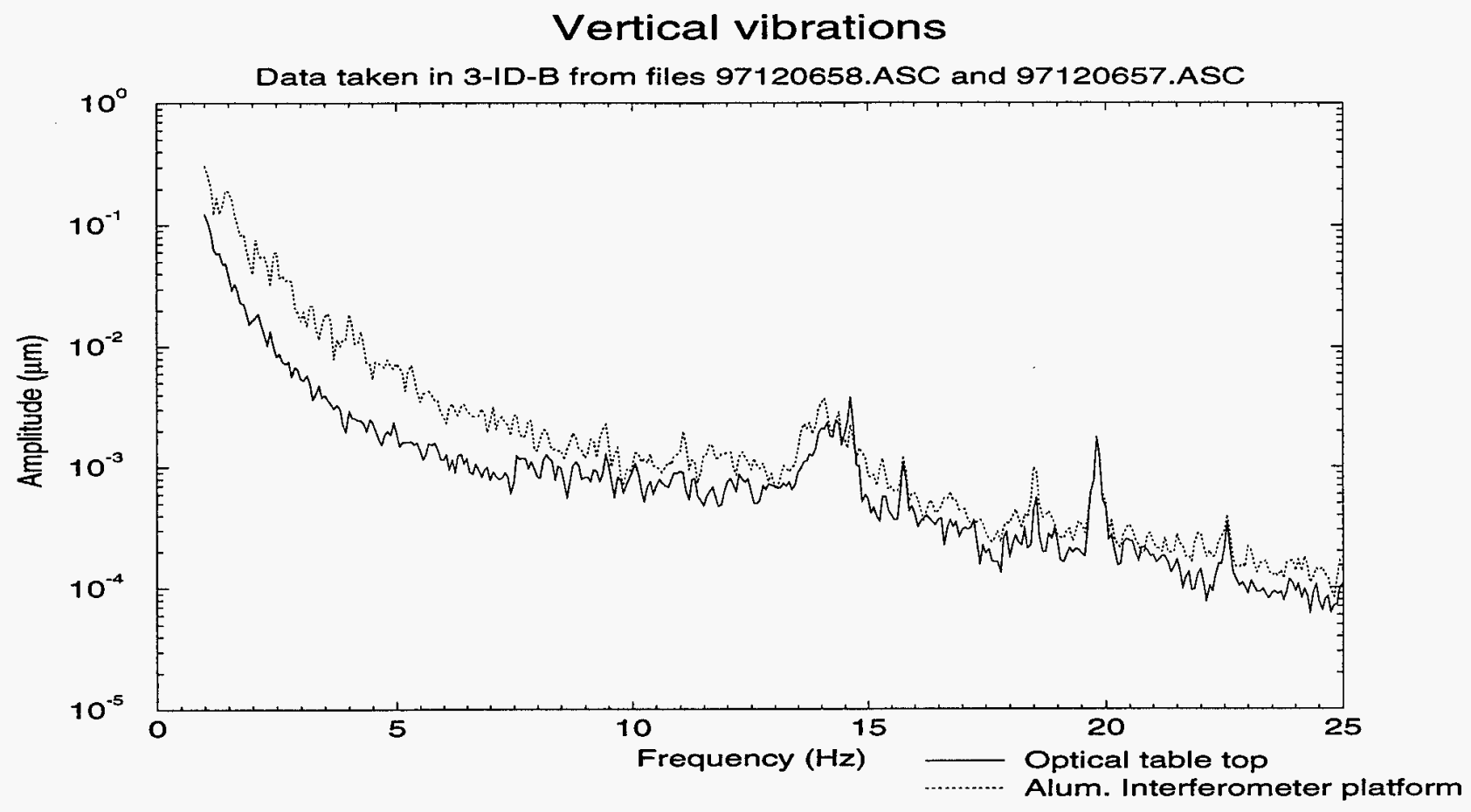

Figure 9: V vibrational spectrum on aluminum platform

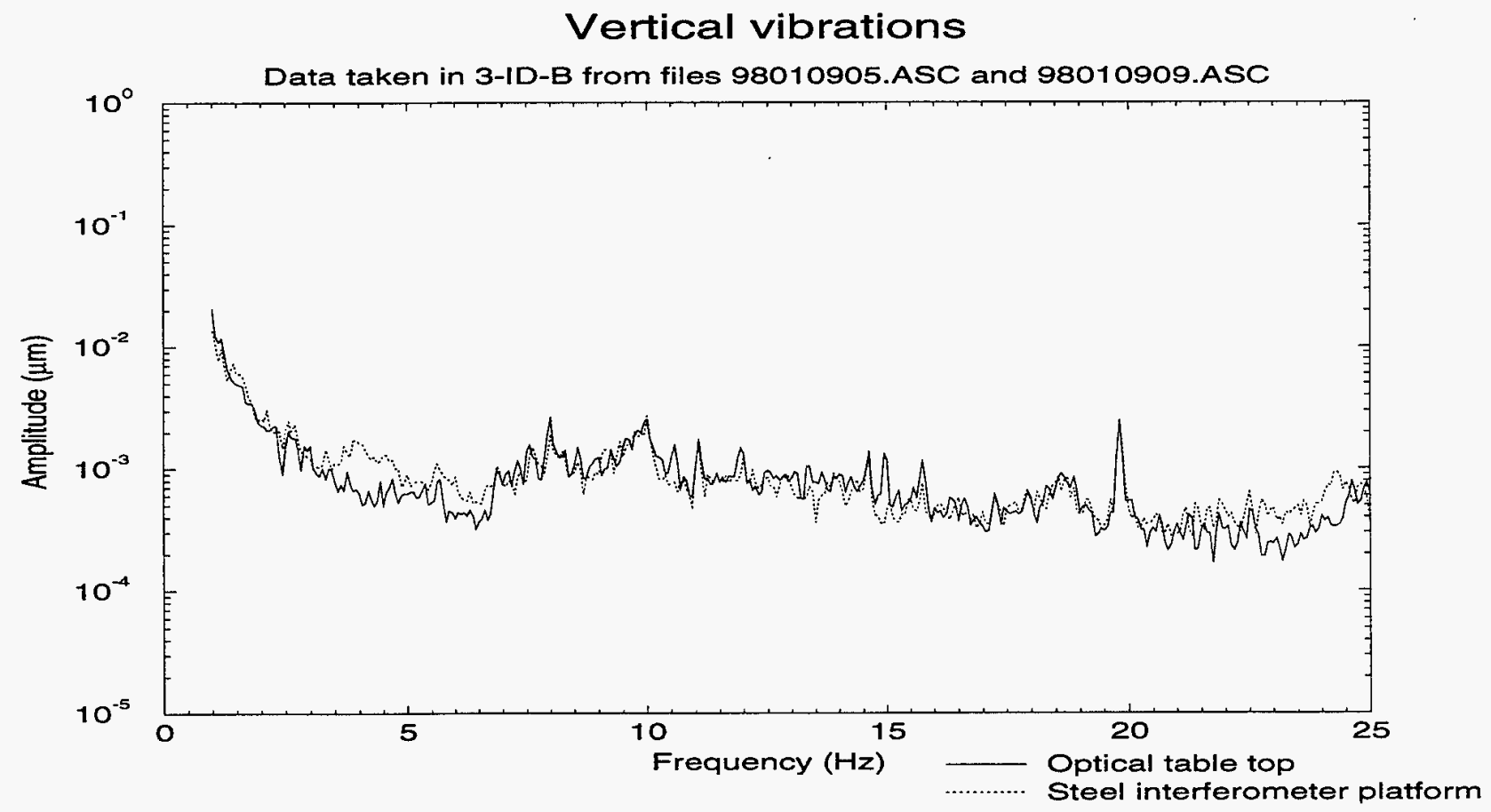

Figure 10: V vibrational spectrum on steel platform 


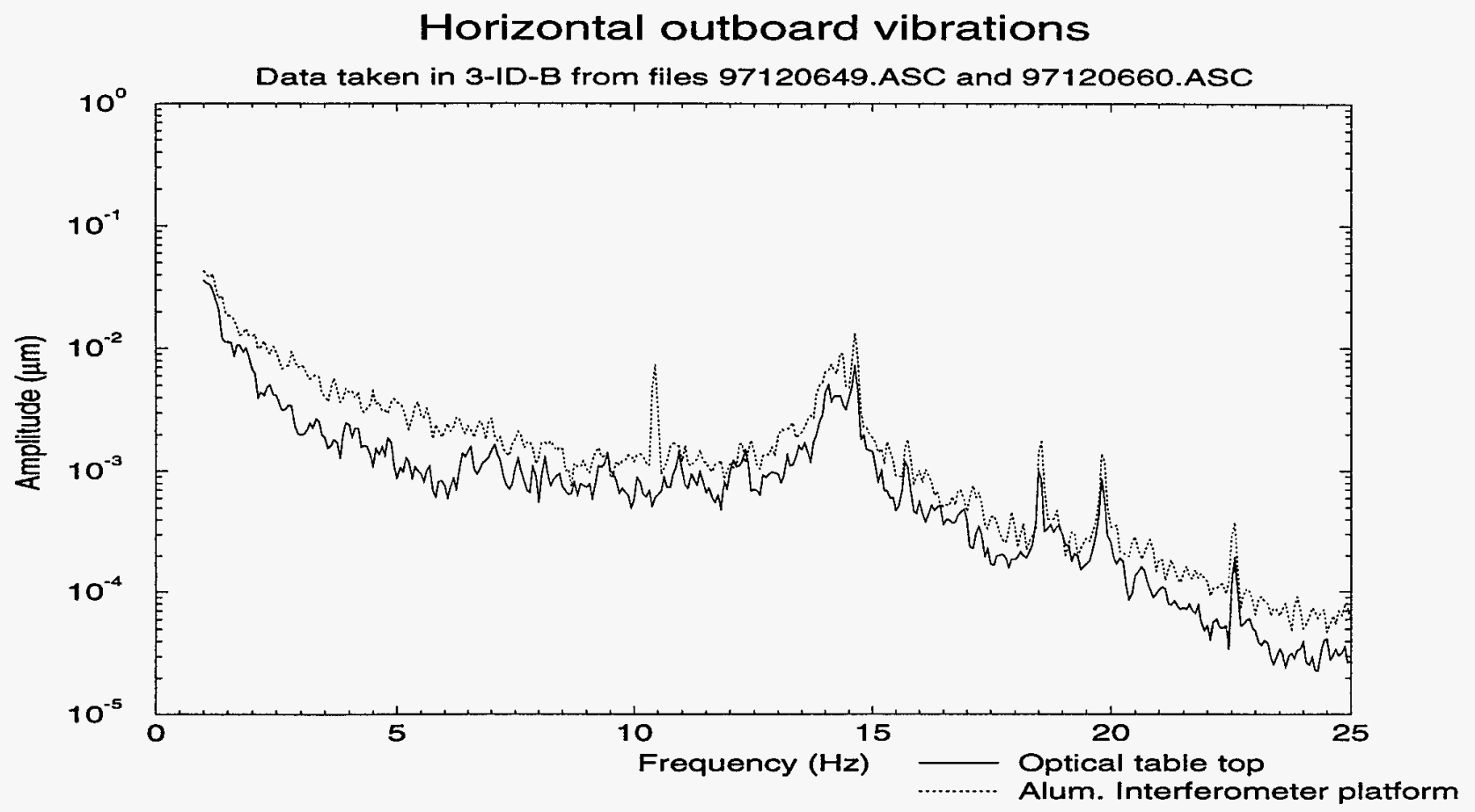

Figure 11: HO vibrational spectrum on aluminum platform

Horizontal outboard vibrations

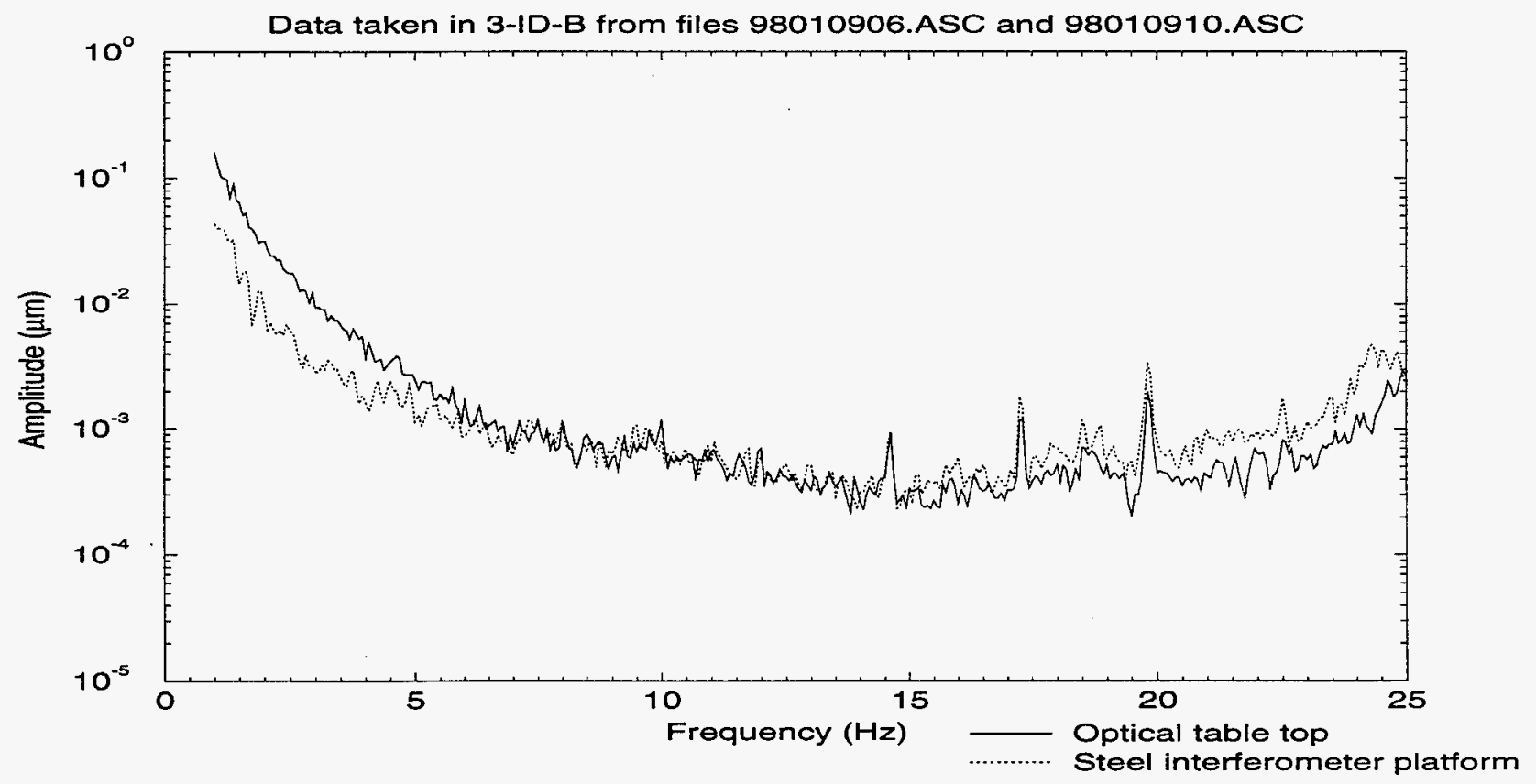

Figure 12: HO vibrational spectrum on steel platform 


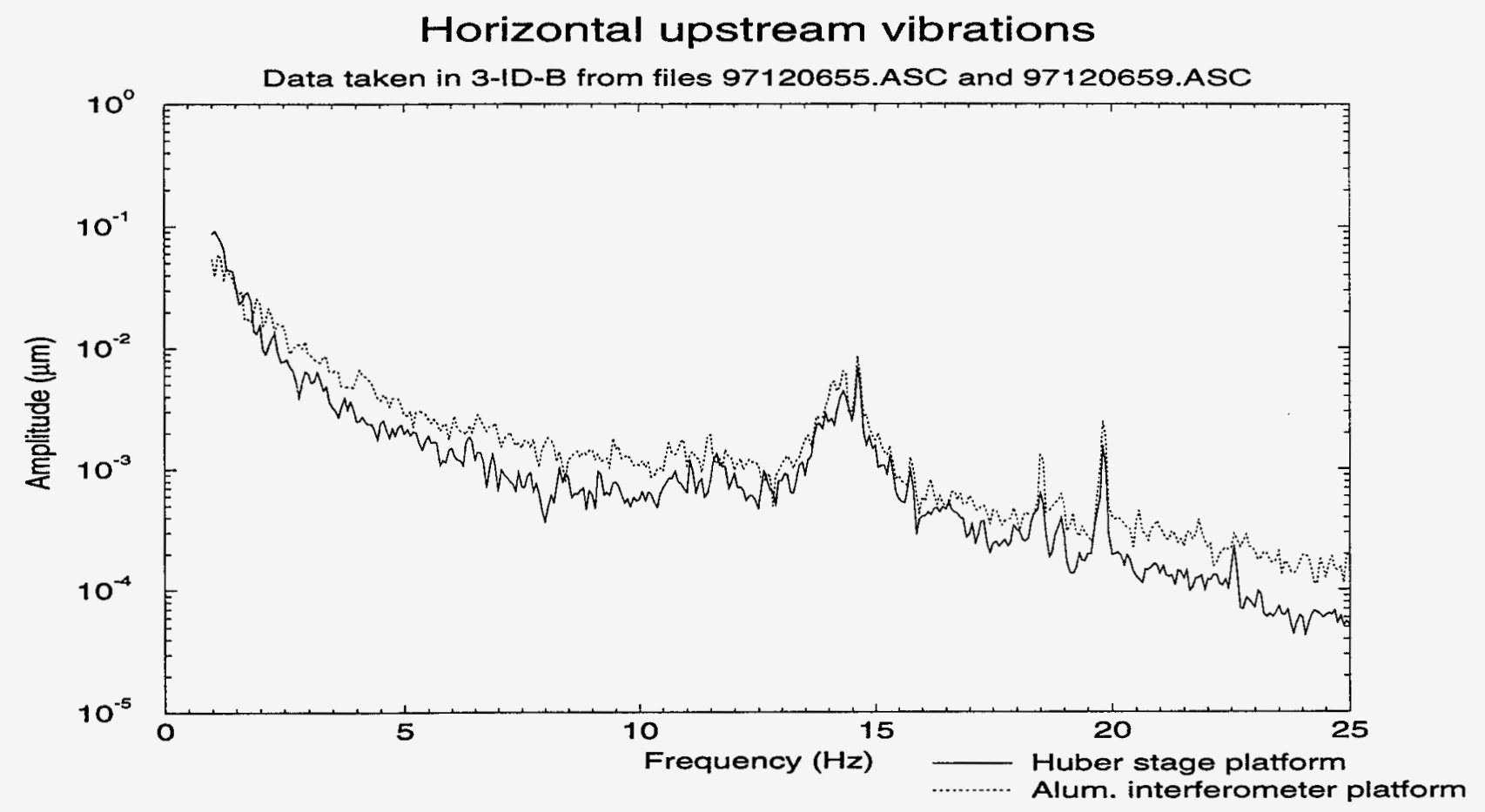

Figure 13: HU vibrational spectrum on aluminum platform

Horizontal upstream vibrations

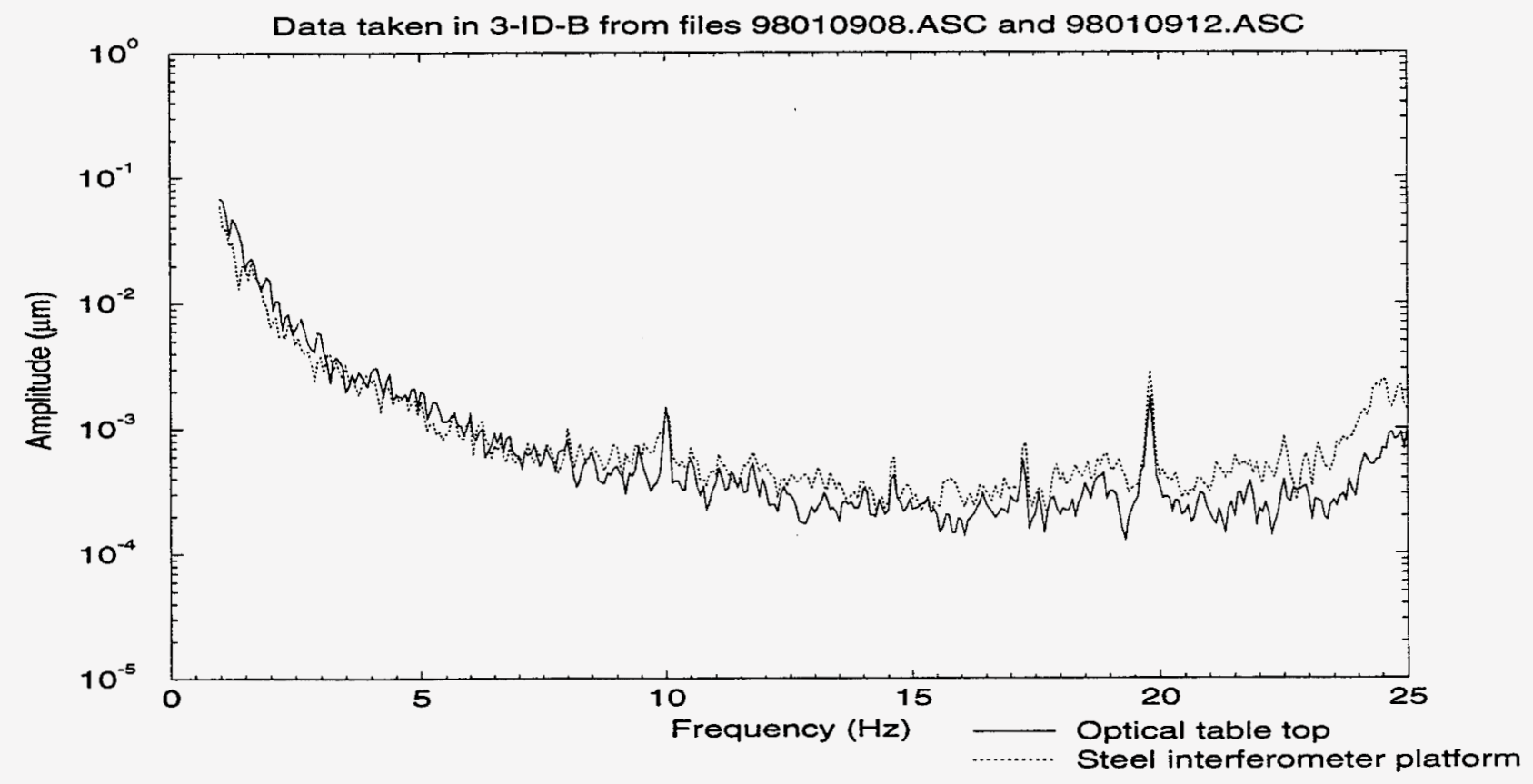

Figure 14: HL vibrational spectrum on steel platform 
Report Number (14) $\angle S--265$ (ANL)

Publ. Date (11) $\frac{199804}{D O E / E R, X F}$
Sponsor Code (18)
UC Category (19)

